\title{
Disposal Criticality Analysis Methodology for Fissile Waste Forms
}

J. Wesley Davis, Framatome Cogema Fuels

and Dr. Peter Gottlieb, TRW

Civilian Radioactive Waste Management System, Management and Operating Contractor 1180 Town Center Drive

Las Vegas, NV 89134

(702)295-4557 / (702)295-4381

\section{Background}

A general methodology has been developed to evaluate the criticality potential of the wide range of waste forms planned for geologic disposal ${ }^{1}$. The range of waste forms include commercial spent fuel, high level waste, DOE spent fuel (including highly enriched), MOX using weapons grade plutonium, and immobilized plutonium. The disposal of these waste forms will be in a container with sufficiently thick corrosion resistant barriers to prevent water penetration for up to 10,000 years. The criticality control for DOE spent fuel is primarily provided by neutron absorber material incorporated into the basket holding the individual assemblies. For the immobilized plutonium, the neutron absorber material is incorporated into the waste form itself.

The disposal criticality analysis methodology includes the analysis of geochemical and physical processes that can breach the waste package and affect the waste forms within. In order to produce criticality, such processes must lead to the separation of the neutron absorber from the fissile material, and also lead to the accumulation of sufficient water to provide moderation. The 


\section{DISCLAIMER}

This report was prepared as an account of work sponsored by an agency of the United States Government. Neither the United States Government nor any agency thereof, nor any of their employees, makes any warranty, express or implied, or assumes any legal liability or responsibility for the accuracy, completeness, or usefulness of any information, apparatus, product, or process disclosed, or represents that its use would not infringe privately owned rights. Reference herein to any specific commercial product, process, or service by trade name, trademark, manufacturer, or otherwise does not necessarily constitute or imply its endorsement, recommendation, or favoring by the United States Government or any agency thereof. The views and opinions of authors expressed herein do not necessarily state or reflect those of the United States Government or any agency thereof. 
separation of fissile material from the neutron absorber material may be accomplished by the removal of the neutron absorber from the waste package (leading to criticality internal to the waste package) or by removal of the fissile material from the waste package with subsequent reconcentration (leading to criticality external to the waste package). The time period of interest is from 10,000 years to several hundred thousand years.

The basic purpose of the methodology is to guide the criticality control features of the waste package design, and to demonstrate that the final design meets the criticality control licensing requirements. The methodology can also be extended to the analysis of criticality consequences (primarily increased radionuclide inventory), which will support the total performance assessment for the repository.

\section{Methodology Summary}

The disposal criticality analysis methodology can be summarized with the following steps. They apply to all waste forms.

1. The possible processes that can lead to criticality have been identified and combined into a preliminary set of scenarios by a group of experts (representing the disciplines of geology, geochemistry, groundwater hydrology, metal corrosion, and neutronics) gathered in a workshop. The resulting scenario set has been documented, including the values to be used for environmental and material performance parameters (ranges or probability distributions).

2. The chemical and geochemical processes acting on the waste package, the waste form, and any criticality control material are analyzed theoretically (using the recognized geochemical computer code, $\mathrm{EQ} 3 / 6)$ to determine the solubilities and concentrations of neutronically 
significant species released by the degradation of the initial waste forms. Particular attention is given to estimating the composition and amounts of the following: (1) precipitates within the waste package which contain neutronically significant material, (2) precipitates or adsorbates in fractures or other voidspace in the rock. If the end results of such scenarios are found to have sufficient fissile material, in the appropriate geometry, with sufficient moderator, and separated from most of the neutron absorber, then they are designated as potentially critical configurations.

3. Parametric criticality analyses are performed on the potentially critical configurations, using variations to identify minimum amounts of degraded structural components (basket, containers) and neutron absorbers which must remain mixed with the fissile material in order to prevent a criticality. The values of $\mathrm{k}_{\text {eff }}$ for specific configurations are calculated using the Monte Carlo neutral-particle transport code MCNP. When a criticality event is possible, the probability distribution functions of the required conditions or processes are used to calculate the probability of the configuration. The confirmation of a critical configuration ( $k_{\text {eff }} \geq$ upper subcritical limit) serves as the starting point for design modification(s) to minimize the probability of criticality. This probability minimization is a principal objective of the defense-in-depth policy.

The logic flow of the methodology applied to the generic internal and external criticality control scenarios is illustrated in Figure 1.

\section{Results and Conclusion}

This disposal criticality analysis methodology has thus far been used to demonstrate the effectiveness of the waste package criticality control design (including neutron absorber material) 
for the following waste forms: commercial spent fuel, MOX SNF, DOE-SNF (MIT and ORNL research reactor fuels), and immobilized plutonium. Representative results are described separate papers presented in this session. These results also include the demonstration that, if a criticality were to occur, the consequences, as measured by the increased radionuclide inventory, are negligible when compared with the radionuclide inventory already present in the waste form. The comprehensive description of the methodology is being presented as a topical report to the U.S. Nuclear Regulatory Commission for their review and approval.

\section{Acknowledgement}

This work was supported by the U. S. Department of Energy, Yucca Mountain Site

Characterization Office as part of the Civilian Radioactive Waste Management Program.

\section{References}

1. Disposal Criticality Analysis Methodology Technical Report, DI Number: B0000000001717-5705-00020 REV 01, CRWMS M\&O, September 1997. 


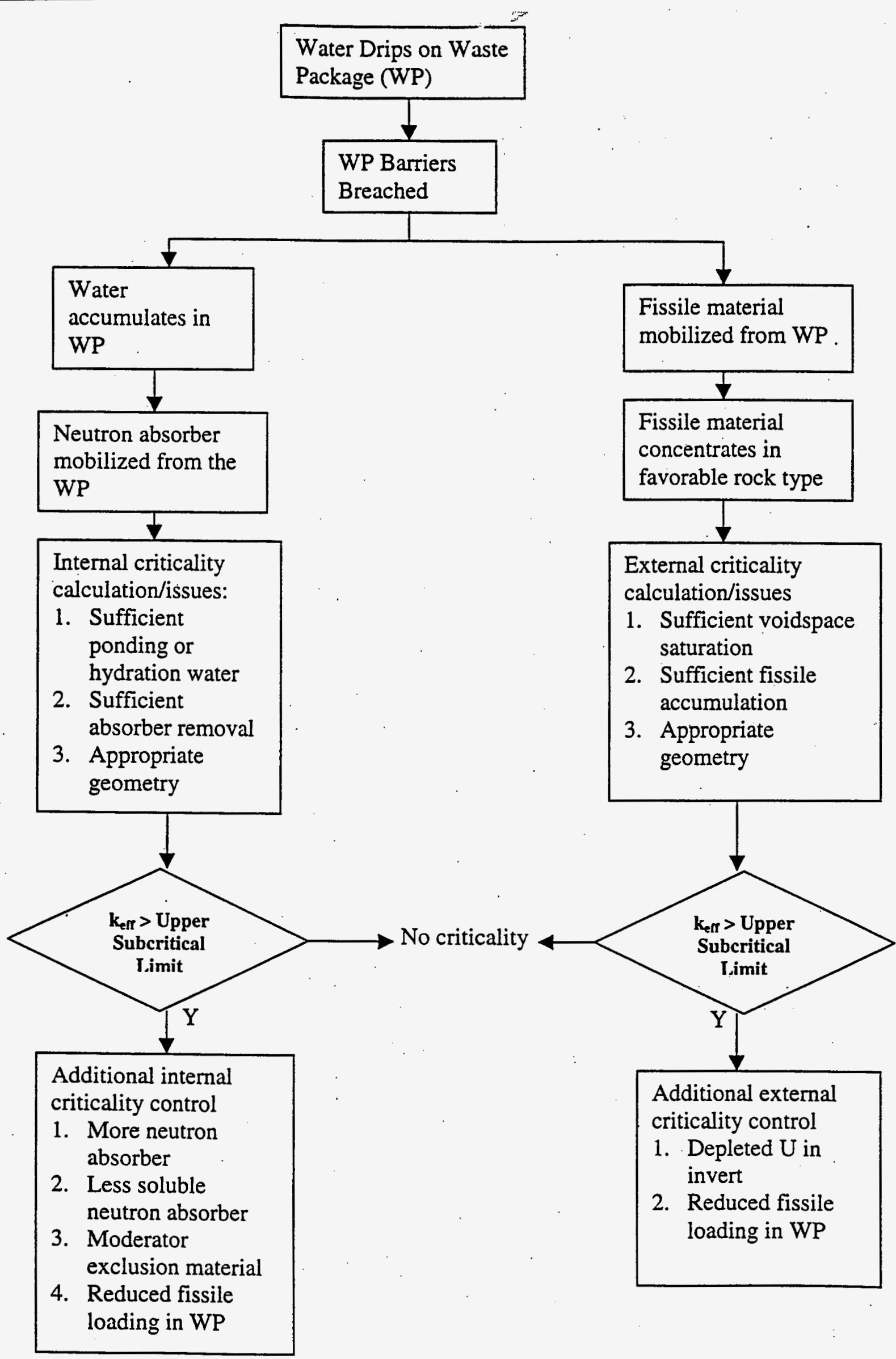

Figure 1. Logic Flow for Disposal Criticality Analysis Methodology 


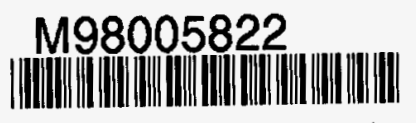

Report Number (14) DOE/RW-- 98005822

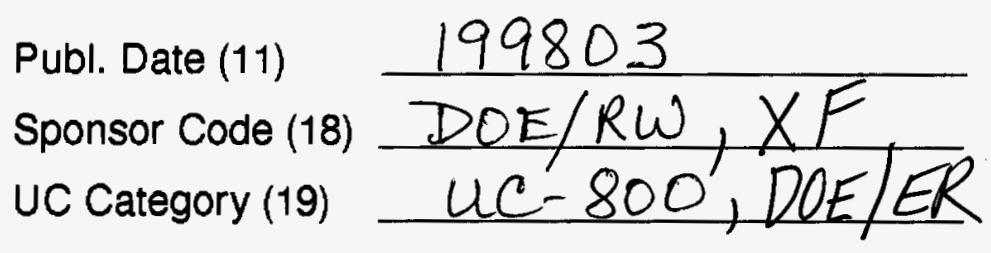

